\title{
Electronic medical record: data collection and reporting for spinal cord injury
}

\author{
Fin Biering-Sørensen ${ }^{1} \cdot$ Stacey Cohen ${ }^{2} \cdot$ Gianna Maria Rodriguez $^{3} \cdot$ Kelly Tausk ${ }^{4} \cdot$ Josh Martin $^{4}$
}

Received: 5 February 2018 / Revised: 1 June 2018 / Accepted: 1 June 2018

(C) International Spinal Cord Society 2018

\begin{abstract}
Study design Presentation of implementation of International Spinal Cord Injury (SCI) Data Sets, International Standards for Neurological Classification of SCI (ISNCSCI), and other structured SCI tools in to the Electronic Medical Record (EMR) Epic.

Objectives To describe the implementation of SCI tools in Epic at Rigshospitalet, University of Hospital, Capital Region of Denmark, and the ambitions for the future development of SCI related structured data and their reporting in the Epic EMR to be able to standardize data collection to facilitate research within institutions and collaboratively with other institutions locally and globally.

Setting Denmark and United States of America.

Methods The general content of the EMR Epic and the SCI-specific structured data implemented are described as well as the tools for reporting.

Results The ISNCSCI is made available via access to http://isncscialgorithm.azurewebsites.net/. After filling in the test data on the website, one can save the completed form as an image within the patient's chart. The International SCI Core Data Set and 13 International SCI Basic Data Sets (Table 1) are nearly completely implemented in the Danish version of Epic as SmartForms. In addition, 14 functional measures, including the Spinal Cord Independence Measure III, are implemented as flowsheets (Table 2).

Conclusions The possibility of entering international recognized structured data into the EMR gives better possibility for data sharing across SCI centers worldwide.

Sponsorship Gianna Maria Rodriguez, Stacey Cohen, and Fin Biering-Sørensen are users of Epic, but have no economic relationship with Epic. Kelly Tausk and Josh Martin are employees of Epic.
\end{abstract}

\section{Introduction}

The Clinic for Spinal Cord Injuries, Rigshospitalet, Denmark covers the population ( 2.8 million) of all East Denmark, Greenland and the Faroe Islands with treatment and

Fin Biering-Sørensen

fin.biering-soerensen@regionh.dk

1 Clinic for Spinal Cord Injuries, Neuroscience Center, Rigshospitalet, University of Copenhagen, Copenhagen, Denmark

2 Clinical Informatics, Mount Sinai Health System, New York, NY, USA

3 Physical Medicine and Rehabilitation, University of Michigan Hospital System, Ann Arbor, MI, USA

4 Epic Systems Corporation, Verona, WI, USA rehabilitation of individuals with spinal cord injury (SCI) after their acute and intensive management is finished. Since 1999 the Clinic for Spinal Cord Injuries had a structured multidisciplinary Electronic Medical Record (EMR) [1], named SCIBase (Spinal Cord Injury dataBase) in function. SCIBase is based on structured discipline specific checklists, including text generation from corresponding on-screen checkboxes etc. Users can document both structured and free text information. From the outset internationally used structured data was included [2-7]. Over the years the update of the International Standards for Neurological Classification of SCI (ISNCSCI) [8] and various International SCI Data Sets were implemented [9-23]. In November 2013, the Capital Region and Region Zealand of Denmark began a 2.5 year project to roll out the EMR from Epic Systems Corporation in Verona, Wisconsin, USA. Due to the longstanding use of SCIBase, there 
was concern regarding the possibility to retain these benefits when implementing Epic. Therefore contacts were taken to United States (US) SCI centers already using Epic during the 2014 Annual Scientific Meeting for American Spinal Injury Association (ASIA) held in San Antonio, Texas, USA May 14-17. Representatives from several of these centers were shown the SCIBase contents of structured data and how these could be extracted into Excel sheets. All found this was a great progress regarding functionality in the EMR. On this background a meeting was held July 17, 2014 at Epic headquarters in Verona, Wisconsin, USA, where SCIBase and ISNCSCI were demonstrated. Epic representatives expressed their willingness to implement the ISNCSCI and International SCI Data Sets into the system.

This article describes the work done in this up until the Epic "go-live" on November 4, 2016 at Rigshospitalet, University of Copenhagen, Capital Region of Denmark, and the ambitions for the future development of SCI related structured data and their reporting in this Epic EMR to work on standardizing data collection to promote and expedite research and collaboration.

\section{Content of the electronic medical record Epic}

The Epic EMR provides a variety of clinical tools across the spectrum of care. EpicCare Inpatient and EpicCare Ambulatory are two core clinical applications in the EMR used for inpatient documentation and outpatient documentation, respectively.

Flowsheets and SmartForms are two tools used to enter information in a standardized manner and to capture discrete data. This information can be extracted for analysis through Epic's reporting infrastructure, which includes Reporting Workbench, Clarity, and the Caboodle data warehouse, etc. Reporting Workbench is a tool that provides flexible, template-based reporting integrated with Epic. Clarity is an Epic application that stores data on a dedicated analytical reporting server in a relational format, organized as tables and columns. Caboodle is Epic's enterprise data warehouse. When implementing Epic, healthcare organizations design and create SmartForms and flowsheets to allow ease of storing, retrieving, and displaying data in the context of Epic's reporting infrastructure.

Flowsheets are the backbone for most structured documentation. They offer integration of entered data across health professionals. They capture information as discrete data, and Epic-released flowsheets can be shared across institutions. In most cases, flowsheets capture longitudinal data better than SmartForms, as they can be filled out multiple times during an encounter.

SmartForms are highly customizable assessments to acquire problem or specialty-specific data. Answers to
SmartForm questions are recorded in SmartData Elements and are available across all applications. SmartData Elements are accessible for reporting purposes and can display information in print groups and notes via Epic SmartTools.

Epic-released SmartData Elements and SmartForms can be shared across institutions through Special Updates from Epic.

SmartTexts and SmartPhrases generate text blocks or templates that can be used to write notes or frequently documented phrases, and they often contain SmartLists, SmartLinks, and SmartBlocks, which can display information captured elsewhere in the chart.

MyChart is a Patient Portal, which allows patients to communicate directly with clinicians and other medical staff.

With Epic users can have access to information in clinical notes, orders, medications, results from diagnostic investigations, communications, etc. in the same place.

\section{Specific Spinal Cord Injury structured data}

The ISNCSCI algorithm is currently available in Epic via an embedded link to: http://isncscialgorithm.azurewebsites.net/ [24]. Its use is consistent with the Terms of Use which users must attest and agree to before using the algorithm. Clinicians can fill in the form on the website which calculates the neurological level of injury, ASIA impairment scale score, etc. Afterwards, the clinician can save the completed form and upload it to the patient's chart in the Media section. In the future, the goal is to create this assessment natively in Epic.

The International SCI Core Data Set (version 2.0) [25] and 13 International SCI Basic Data Sets (Table 1) [10, 11, 14-23, 26] are nearly completely implemented in the Danish version of Epic as SmartForms. Experts in the SCI field continue to work with Epic to bring these data sets to the broader Epic community. The remaining five International SCI Basic Data Sets [27-31] excluding the International SCI Non-traumatic Basic Data Set [32] which is more or less included in version 2.0 of the International SCI Core Data Set [25] are either awaiting implementation [31] or only partly implemented because, some data set data elements, e.g., history questions, laboratory results are already tracked in Epic, so there exists a question of where and how to track this data.

Table 2 informs about functional measures which are already implemented as flowsheets in the Danish Epic version.

In SCI rehabilitation, doctors, nurses, and physical or occupational therapists utilize the same documentation tools although they may document different pieces of it depending on the setting the patient is in. For example, typically a doctor fills in ISNCSCI in the acute setting while 
Table 1 International Spinal Cord Injury (SCI) Data Sets nearly completely implemented into the Danish version of the electronic medical record Epic

International SCI Core Data Set

International SCI Spinal Column Injury Basic Data Set

International SCI Spinal Interventions and Surgical Procedures Basic Data Set

International SCI Lower Urinary Tract Function Basic Data Set

International SCI Urinary Tract Infection Basic Data Set

International SCI Urodynamic Basic Data Set

International SCI Urinary Tract Imaging Basic Data Set

International SCI Bowel Function Basic Data Set

International SCI Female Sexual and Reproduction Function Basic Data Set

International SCI Male Sexual Function Basic Data Set

International SCI Musculoskeletal Basic Data Set

International SCI Upper Extremity Basic Data Set

International SCI Pain Basic Data Set

International SCI Quality of Life Basic Data Set

Table 2 Functional measures implemented as flowsheets in the Danish version of the Epic electronic medical record

Spinal Cord Independence Measure III (SCIMIII)

Canadian Model of Occupational Performance (COMP)

Gugging Swallowing Screen (GUSS)

Forced Vital Capacity (FVC)

Peak Expiratory Flow (PEF)

Modified Ashworth Scale (MAS)

Penn Scale

Grasp and Release Test

Timed Up and Go (TUG)

Berg Balance Scale

Walking Index Spinal Cord Injury (WISCI)

6 min Walk Test (6MWT)

$10 \mathrm{~m}$ Walk Test (10MWT)

Wheelchair Skills Test.

the physical therapist does it in the rehabilitation setting; doctors may use the International SCI Basic Data Sets for Lower Urinary Tract and Bowel Function when admitting the patient, while the nurse fills them in at discharge. These observations and documentation are then included in the discharge letter or other communications to the patient's care team including the general practitioner. The International SCI Upper Extremity Basic Data Set is filled in by the occupational therapists during the inpatient rehabilitation period. The International SCI Quality of Life Basic Data Set may be used by all professions but is mostly used by the doctors and the nurses.

The flowsheets listed in Table 2 are primarily filled in by the therapists whenever appropriate.

\section{Tools for reporting in Epic}

Registries group patients together based on identifying traits. Epic's chronic disease and wellness registries are collections of patients who match a specified definition, plus a list of relevant clinical information about those patients to simplify and speed reporting on population subsets. Epic's contact-based registries collect patient encounters of a specified type and gather information about documentation compliance and consistency across those encounters.

Radar provides a centralized location for reporting tools and metrics using home workspaces called dashboards. Radar users can view, access, and manipulate reports.

Caboodle, Epic's enterprise data warehouse platform, can combine Epic and external data in reports, dashboards, and self-service reporting tools.

SlicerDicer is a self-service reporting tool allowing customizable data exploration abilities to sift through large populations of patients.

Reporting Workbench is a reporting tool available across Epic applications. Users can run administrator-created reports or build their own reports from templates. These reports can display discrete data captured in flowsheets and SmartData Elements via SmartForms, and these reports can be exported into Excel files for research purposes within and across institutions.

Interfacing with external registries and databases requires discussions with each organization's Epic contacts and data infrastructure champions on the feasibility of such a data exchange. Several members of the Epic community have successfully connected to national or international patient registries or databases via interface or extract. For example, most organizations in the US exchange uni- or bi-directional data with local or state immunization registries. In Epic, it is possible to configure contact- or patient-based extracts to local, state, or national registries for quality or regulatory reporting needs.

\section{Present development}

This group came together to pioneer efforts to provide access to standardized information, initially with the International SCI Data Sets, for SCI provider Epic users. This development will eliminate the need to use a different system to fill out and report on SCI data. Stakeholders and experts from throughout the SCI provider community of Epic users collaborate with Epic on a bimonthly basis to establish best practice documentation tools within Epic and to give feedback on designs. This group continues to work together and aims to make most of these tools available in Epic's Foundation System in late 2018. The Foundation System is delivered to all new Epic customers, and existing customers can obtain updates to their system by incorporating Foundation System updates. As the 
SCI data sets are implemented in Epic, the Epic team will create Turbocharger packages which allow healthcare organizations already live on Epic to take in the latest Foundation System updates. All Epic organizations partner with members from Technical Services and sometimes staff from Implementation to implement periodic updates to their systems.

\section{Discussion}

EMRs are widely used in SCI centers today, but implementation of internationally recognized structured SCI data seems less common. At least literature about general utilization of structured SCI data in EMR is difficult to find!

Structured SCI instruments like ISNCSCI and SCIM III are known to be used worldwide, as these are included in many reported studies, and we are aware that the International SCI Data Sets are currently being used within the international SCI community in an increasing number of registries worldwide, including in all eight SCI centers in the Netherlands (13 data sets), the Nordic SCI Registry (2 data sets), the Rick Hansen SCI Registry in Canada (7 data sets), Victoria, Australia (being extended nationally) (9 data sets), and a prevention registry covering India, Nepal, Sri Lanka, Bangladesh, Malaysia, and Thailand (1 data set). Others may as well be out there as we know several of the International SCI Data Sets have been translated into Chinese, Dutch, Spanish, Portuguese, Italian, French, Danish, Swedish, Norwegian, Finnish, Icelandic, Korean, and maybe other languages.

In most of these instances, the structured SCI data are used for research purposes including in registries where data may need to be entered separately, i.e., the data is not collected directly in the EMR in daily clinical practice. Because, e.g., the International SCI Basic Data Sets are meant to be collected as a minimum amount of information necessary for the patient evaluation, monitoring, and treatment [33], it would seem optimal to collect these as standardized data in the EMR. When clinicians are able to collect standardized data in the EMR, it will be easier and more straightforward to retrieve these data for administrative as well as research purposes. If internationally recognized data is collected in a standardized manner, developing multicenter trials will be a more realistic possibility since comparisons with other centers will be much easier to accomplish. This data collection method increases the ability for data sharing across SCI centers locally and worldwide.

\section{Compliance with ethical standards}

Conflict of interest Gianna Maria Rodriguez, Stacey Cohen, and Fin Biering-Sørensen are users of Epic, but have no economic relationship with Epic. Kelly Tausk and Josh Martin are employees of Epic.

\section{References}

1. Biering-Sørensen F, Gregersen H, Hansen HV, Nielsen L, Ranneries P, Rolfsager K, et al. Tværfaglig elektronisk patientjournal og kliniks database i ét. SCIBase. Ugeskr Læg. 2001;163:3207-12.

2. American Spinal Injury Association/ and International Medical Society of Paraplegia ASIA/IMSOP. International Standards for Neurological and Functional Classification of Spinal Cord Injury. Chicago, IL: American Spinal Injury Association; 1996.

3. Bohannon RW, Smith MB. Interrater reliability of a modified Ashworth scale of muscle spasticity. Phys Ther. 1987;67:206-7.

4. Penn RD, Savoy SM, Corcos D, Latash M, Gottlieb G, Parke B, et al. Intrathecal baclofen for severe spinal spasticity. N Engl J Med. 1989;320:1517-21.

5. Daniel RK, Hall EJ, MacLeod MK. Pressure sores - a reappraisal. Ann Plast Surg. 1979;3:53-63.

6. Levi R, Ertzgaard P. Quality indicators in spinal cord injury care: a Swedish collaborative project. The Swedish Spinal Cord Injury Council 1998. Scand J Rehabil Med Suppl. 1998;38:1-80.

7. Sollerman C, Ejeskär A. Sollerman hand function test. Scand J Plast Reconstr Surg. 1995;29:167-76.

8. Kirshblum SC, Burns SP, Biering-Sorensen F, Donovan W, Graves DE, Jha A, et al. International standards for neurological classification of spinal cord injury (Revised 2011). J Spinal Cord Med. 2011;34:535-46.

9. DeVivo M, Biering-Sørensen F, Charlifue S, Noonan V, Post M, Stripling $\mathrm{T}$, et al. International Spinal Cord Injury Data Sets. Spinal Cord. 2006;44:535-40.

10. Biering-Sørensen F, Craggs M, Kennelly M, Schick E, Wyndaele JJ. International Lower Urinary Tract Function Basic Spinal Cord Injury Data set. Spinal Cord. 2008;46:325-30.

11. Biering-Sørensen F, Craggs M, Kennelly M, Schick E, Wyndaele JJ. International Urodynamic Basic Spinal Cord Injury Data Set. Spinal Cord. 2008;46:513-6.

12. Widerström-Noga E, Biering-Sørensen F, Bryce T, Cardenas DD, Finnerup NB, Jensen MP, et al. The International Spinal Cord Injury Pain Basic Data Set. Spinal Cord. 2008;46:818-23.

13. Krogh K, Perkash I, Stiens SA, Biering-Sørensen F. International Bowel Function Basic Spinal Cord Injury Data Set. Spinal Cord. 2009;47:230-4.

14. Biering-Sørensen F, Craggs M, Kennelly M, Schick E, Wyndaele J-J. International Urinary Tract Imaging Basic Spinal Cord Injury Data Set. Spinal Cord. 2009;47:379-83.

15. Alexander MS, Biering-Sørensen F, Elliott S, Kreuter M, Sønksen J. International Spinal Cord Injury Female Sexual And Reproductive Function Basic Data Set. Spinal Cord. 2011;49:787-90. https://doi.org/10.1038/sc.2011.7

16. Alexander MS, Biering-Sørensen F, Elliott S, Kreuter M, Sønksen J. International Spinal Cord Injury Male Sexual Function Basic Data Set. Spinal Cord. 2011;49:795-8. https://doi.org/10.1038/sc. 2010.192

17. Charlifue S, Post MW, Biering-Sørensen F, Catz A, Dijkers M, Geyh S, et al. International Spinal Cord Injury Quality Of Life Basic Data Set. Spinal Cord. 2012;50:672-5. https://doi.org/10. $1038 /$ sc. 2012.27

18. Biering-Sørensen F, Burns AS, Curt A, Harvey LA, Jane Mulcahey M, Nance PW, et al. International Spinal Cord Injury Musculoskeletal Basic Data Set. Spinal Cord. 2012;50:797-802. https://doi.org/10.1038/sc.2012.102

19. Dvorak MF, Wing PC, Fehlings MG, Vaccaro AR, Itshayek E, Biering-Sorensen F, et al. International Spinal Cord Injury Spinal Column Injury Basic Data Set. Spinal Cord. 2012;50:817-21. https://doi.org/10.1038/sc.2012.60 
20. Goetz LL, Cardenas DD, Kennelly M, Bonne Lee BS, Linsenmeyer T, Moser C, et al. International Spinal Cord Injury Urinary Tract Infection Basic Data Set. Spinal Cord. 2013;51:700-4. https://doi.org/10.1038/sc.2013.72

21. Widerström-Noga E, Biering-Sørensen F, Bryce TN, Cardenas DD, Finnerup NB, Jensen MP, et al. The International Spinal Cord Injury Pain Basic Data Set (version 2.0). Spinal Cord. 2014;52:282-6. https://doi.org/10.1038/sc.2014.4

22. Biering-Sørensen F, Bryden A, Curt A, Friden J, Harvey LA, Mulcahey MJ, et al. International Spinal Cord Injury Upper Extremity Basic Data Set. Spinal Cord. 2014;52:652-57. https:// doi.org/10.1038/sc.2014.87

23. Dvorak MF, Itshayek E, Fehlings MG, Vaccaro AR, Wing PC, Biering-Sorensen F, et al. International Spinal Cord Injury: Spinal Interventions And Surgical Procedures Basic Data Set. Spinal Cord. 2015;53:155-65. https://doi.org/10.1038/sc.2014.182

24. Walden K, Bélanger LM, Biering-Sørensen F, Burns SP, Echeverria $\mathrm{E}$, Kirshblum $\mathrm{S}$, et al. Development and validation of a computerized algorithm for International Standards for Neurological Classification of Spinal Cord Injury (ISNCSCI). Spinal Cord. 2016;54:197-203. https://doi.org/10.1038/sc.2015.137

25. Biering-Sørensen F, DeVivo MJ, Charlifue S, Chen Y, New PW, Noonan V, et al. International Spinal Cord Injury Core Data Set (version 2.0)-including standardization of reporting. Spinal Cord. 2017;55:759-64. https://doi.org/10.1038/sc.2017.59

26. Krogh K, Emmanuel A, Perrouin-Verbe B, Korsten MA, Mulcahey MJ, Biering-Sørensen F International Spinal Cord Injury
Bowel Function Basic Data Set (Version 2.0). Spinal Cord. 2017;55:692-8 https://doi.org/10.1038/sc.2016.189.

27. Krassioukov A, Alexander MS, Karlsson AK, Donovan W, Mathias CJ, Biering-Sørensen F. International Spinal Cord Injury Cardiovascular Function Basic Data Set. Spinal Cord. 2010;48:586-90.

28. Biering-Sørensen F, Krassioukov A, Alexander MS, Donovan W, Karlsson AK, Mueller G, et al. International Spinal Cord Injury Pulmonary Function Basic Data Set. Spinal Cord. 2012;50:418-21. https://doi.org/10.1038/sc.2011.183

29. Karlsson AK, Krassioukov A, Alexander MS, Donovan W, Biering-Sørensen F. International Spinal Cord Injury Skin and Thermoregulation Function Basic Data Set. Spinal Cord. 2012;50:512-6. https://doi.org/10.1038/sc.2011.167

30. Bauman WA, Biering-Sørensen F, Krassioukov A. The international spinal cord injury endocrine and metabolic function basic data set. Spinal Cord. 2011;49:1068-72. https://doi.org/10.1038/sc.2011.51

31. Post MW, Charlifue S, Biering-Sørensen F, Catz A, Dijkers MP, Horsewell J, et al. Development of the International Spinal Cord Injury Activities and Participation Basic Data Set. Spinal Cord. 2016;54:530-34. https://doi.org/10.1038/sc.2015.188

32. New PW, Marshall R. International Spinal Cord Injury Data Sets for non-traumatic spinal cord injury. Spinal Cord. 2014;52:123-32. https://doi.org/10.1038/sc.2012.160

33. Biering-Sørensen F, Charlifue S, DeVivo M, Noonan V, Post M, Stripling T, et al. International Spinal Cord Injury Data Set. Spinal Cord. 2006;44:530-4. 